\title{
Jeanne Favret-Saada, os afetos, a etnografia
}

\author{
Marcio Goldman \\ Professor Adjunto do PPGAS/MN/UFRJ; pes- \\ quisador do CNPq e bolsista da FAPERJ; autor \\ de Razão e Diferença. Afetividade, Racionalidade e \\ Relativismo no Pensamento de Lévy-Brubl (1994), \\ Alguma Antropologia (1999) e Como Funciona a \\ Democracia. Uma Teoria Etnográfica da Politica \\ (no prelo), além de co-organizador de Antropolo- \\ gia, Voto e Representação Política (1996). Realiza \\ trabalho de campo sobre política, etnicidade e \\ religióes afro-brasileiras em Ilhéus, sul da Bahia.
}

Se o escritor é um feiticeiro é porque escrever é um devir, escrever é atravessado por estranhos devires que não são devires-escritor, mas devires-rato, devires-inseto, devires-lobo etc.

Gilles Deleuze e Félix Guattari

Jeanne Favret-Saada faz parte desse grupo de autores conhecidos por terem escrito um livro. Neste caso, ainda que isso fosse inteiramente verdadeiro, não se poderia dizer que trata-se de pouca coisa. Les Mots, la Mort, les Sorts é uma maravilha etnográfica e, ao mesmo tempo, uma das raras obras-primas da história do pensamento antropológico. Elaborado e escrito em uma época (não tão distante assim) em que a imagem do pensamento dominante na academia ainda não era construída com os parâmetros empresariais capitalistas da rentabilidade e da produtividade, o livro levou quase dez anos para ficar pronto. Período que envolveu uma longa e intensa pesquisa de campo, conduzida entre 1968 e 1971, sua redação e sua publicação, que só ocorreu em 1977.

Esse tempo - que hoje, certamente, seria considerado apenas uma demora - faz, entre- tanto, parte intrínseca e constitutiva do trabalho. De fato, Favret-Saada não se cansou de relatar, em diversas ocasióes, como os primeiros meses no campo (quase um ano, na verdade) foram, aparentemente, estéreis. Apenas a autora parecia se interessar por seu tema, a feitiçaria; seus interlocutores reagiam, antes, evitando o assunto, negando ou denegando sua própria existência, imputando-o a pessoas tidas como ignorantes ou remetendo-o a um passado já superado há muito tempo.

Se a pesquisa tivesse, então, durado "apenas" um ano (quantos de nós dispomos mesmo desse prazo atualmente?), Favret-Saada não teria muito a dizer além do que pode ser obtido pelo limitado procedimento de investigação que Malinowski já condenava sob o nome de método de pergunta e resposta. Ou do que se pode extrair da consulta de documentos e arquivos onde, como lembra Favret-Saada (1981b: 336), “o 'povo' é falado mais do que fala, aparecendo como o objeto do discurso administrativo, não como o sujeito de um discurso autônomo" produzidos por aqueles mesmos que desprezam e desejam condenar ao silêncio práticas como a feitiçaria. De psiquiatras, jornalistas e dos que 
se consideram parte das elites, não se pode esperar muita coisa quando o tema em questáo parece desafiar suas certezas e até mesmo sua dominação.

O passar do tempo, entretanto, não é apenas o passar do tempo. Esse falso truísmo conduziria apenas às banalidades que repetem que, "com o tempo", os nativos se acostumam com a presença dos etnógrafos e passam a se comportar mais normalmente e até mesmo a relatar a eles seus segredos mais íntimos.

Em lugar de supor que o tempo apenas fornece um meio externo para as relações humanas, é preciso compreender que ele é, ao contrário e em si mesmo, uma relação. Pois é apenas com o tempo, e com um tempo não mensurável pelos parâmetros quantitativos mais usuais, que os etnógrafos podem ser afetados pelas complexas situaçóes com que se deparam - o que envolve também, é claro, a própria percepção desses afetos ou desse processo de ser afetado por aqueles com quem os etnógrafos se relacionam. Foi apenas quando alguém diagnosticou que a etnógrafa fora "pega" (prise) pela feitiçaria que passou a fazer algum sentido falar com ela sobre o assunto.

Não se trata, contudo, de imaginar nenhum crédulo local que, para a felicidade de uma pesquisadora que permaneceria distante e incólume em sua objetividade de cientista, tivesse decidido "acreditar" que ela também fora enfeitiçada. Na verdade, Favret-Saada tinha seus sintomas, de repetidos acidentes de automóvel a um certo tremor das mãos e um brilho diferente no olhar. Sintomas que permitiam levantar a hipótese do enfeitiçamento. Por outro lado, indagar se ela também "acreditava" na feitiçaria é igualmente um exercício cheio de inutilidade, uma vez que náo se trata, justamente, de crença, mas - como o leitor aprenderá no texto da autora aqui traduzido em ótima hora - de afeto. Não de afeto no sentido da emoção que escapa da razáo, mas de afeto no sentido do resultado de um processo de afetar, aquém ou além da representação.

Não há nenhuma necessidade de supor, tampouco, que os afetos de Favret-Saada no mundo em que passara a viver (e que, por um tempo, filtrava também o mundo com o qual ela estava mais habituada e que costumamos chamar de "nosso") fossem idênticos aos sentidos por aqueles que viviam mais longa e cotidianamente, náo a crença, mas a experiência da feitiçaria. Basta que os etnógrafos se deixem afetar pelas mesmas forças que afetam os demais para que um certo tipo de relaçáo possa se estabelecer, relaçáo que envolve uma comunicação muito mais complexa que a simples troca verbal a que alguns imaginam poder reduzir a prática etnográfica. Trata-se em suma, como escreve a autora (Favret-Saada 1990a: 7-9), de conceder "estatuto epistemológico a essas situações de comunicação involuntária e não intencional", evitando a "desqualificação da palavra indígena" em benefício da "promoção da do etnógrafo", assim como a armadilha suprema de imaginar que fazer etnografia significa "explorar as trevas com uma filosofia das Luzes” (Favret-Saada 1981b: 344).

Em função de tudo isso, Les Mots, la Mort, les Sorts não pode ser enquadrado em nenhum dos dois estilos etnográficos contemporâneos mais usuais. Não se trata de apresentar as pessoas e suas açóes (inclusive o que elas dizem e, às vezes, até mesmo o que elas supostamente pensam) como um antigo naturalista descrevia, sobre um mesmo plano, fauna, flora e geografia. Mas não se trata, tampouco - após condenar essa primeira modalidade de descriçáo como empirista, ingênua ou autoritária, na medida em que se arroga o direito de representar o outro -, de voltar-se para dentro, opondo uma suposta transparência do sujeito para si mesmo à opacidade do mundo dos outros. Ao transitar do cientificismo para algo como um certo tipo de autobiografia, o gênero etnográfico não 
parece ter avançado muito: "que um etnógrafo aceite ser afetado não implica que se identifique com o ponto de vista indígena, nem que aproveite a experiência de campo para excitar seu narcisismo" (Favret-Saada 1990a: 7).

$\mathrm{Na}$ verdade, conta a autora (Favret-Saada 2004a), os afetos suscitados no campo, "a despossessão e a perda de controle de si, a aceitação do desejo desconhecido do outro, o reconhecimento de uma opacidade constitutiva da comunicação humana", tudo isso que era "insuportável para os etnólogos", era "banal para os psicanalistas". Por outro lado, bastou que a autora sustentasse que a feitiçaria - ou antes, o desenfeitiçamento - constitui uma forma de terapia que nada deve à psicanálise, para que o cientificismo que os analistas sem dúvida compartilham com os etnólogos impedisse que a acolhida do trabalho de Favret-Saada fosse muito longe. De fato, ela sugere que não se trata, no desenfeitiçamento, nem de uma forma primitiva de lidar com aquilo que só a ciência realmente conhece, nem de uma simples modulação cultural de uma prática universal. Trata-se, antes, de um dispositivo completo, destinado a "ajudar algumas pessoas", dispositivo que funciona tão bem (ou tão mal, segundo os casos) quanto outro qualquer e que deveria ser investigado em conjunto com outras "instituiçóes curativas" - a psicanálise, por exemplo - no contexto de uma "antropologia das terapias” (Favret-Saada 1989b: 55; 1990a: 3).

É uma certa forma de cientificismo, portanto, que explica que tanto etnólogos quanto analistas - por razóes distintas, talvez - tenham, ao mesmo tempo, admirado e recusado Les Mots, la Mort, les Sorts. Como observou a autora (Favret-Saada 2004a), o livro parece ter sido objeto do que Benjamin denominava "incompreensão entusiasta", uma espécie de "quadro famoso, pendurado nas paredes dos departamentos de antropologia, que os estudantes são incitados a admirar sem imitar”.
E, de fato, é quase tão difícil encontrar uma crítica explícita ao livro quanto um trabalho que leve efetivamente a sério as potencialidades por ele abertas.

Para fazê-lo seria preciso abandonar de vez o paradigma cientificista no qual ainda nos movemos em benefício de um método "clínico", no sentido médico e psicanalítico do termo. $\mathrm{Na}$ primeira opção, as escolhas são limitadas: ou procedemos indutivamente, generalizando a partir do maior número possível de casos empíricos, ou dedutivamente, por meio da aplicação a qualquer caso concreto de alguns princípios gerais previamente estabelecidos. Favret-Saada, por outro lado, procede por meio da observação, exame e constituição de casos cuja singularidade não elimina o fato de que cada um pode compartilhar com outros certos elementos e características. Isso faz com que, aos olhos do clínico, cada caso seja, ao mesmo tempo, uma síndrome única e parte de síndromes mais gerais, e que cada um se beneficie indiretamente das anamneses anteriores e contribua para as futuras.

Náo é de admirar, portanto, que o trabalho de Favret-Saada tenha suscitado algumas reações estranhas, tanto na mídia (Favret-Saada 1989b: 112) - onde ela chegou a ser batizada de "a feiticeira do CNRS" (o Centro Nacional de Pesquisa Cientifica) - quanto na academia, onde um colega chegou a sugerir que o CNRS deveria cancelar sua bolsa uma vez que, repudiando a ciência, ela a teria empregado simplesmente para aprender a se tornar uma feiticeira (Favret-Saada 1977a: 287).

Em outras palavras, não são apenas os fantasmas suscitados pela equívoca noção de observação participante que, como sugere a autora (Favret-Saada 1990a: 5-6), tendem a funcionar como obstáculos para o trabalho do etnógrafo. Ela enumera outros: a similaridade cultural excessiva do etnógrafo com o grupo estudado; a concentração da investigação nas elites e/ou nos arquivos; a hipótese de que tudo se esclarece 
uma vez remetido ao "social"; a adoção de noçôes como a de crença ou de ideais como "objetividade" e "cientificidade". Isso não significa, é claro, que o antropólogo não possa estudar a sociedade a que pertence, apenas que isso deve ser feito com os cuidados e os distanciamentos necessários; ou que arquivos e elites tenham de ficar, necessariamente, fora da investigação, apenas que devem ser colocados em seu devido lugar; ou que as situaçóes de enunciação, que não se confundem com simples "contextos", não sejam fundamentais para a análise; ou que as representaçóes nativas, assim como o ideal de conhecimento do antropólogo, não tenham que ser respeitados, uma vez que trata-se sempre, na etnografia, de uma espécie de alinhamento entre esses programas de verdade (cf. Favret-Saada 1977a: 287, passim).

Se fosse, então, inteiramente verdadeiro que Jeanne Favret-Saada é autora de um livro, e se esse livro for Les Mots, la Mort, les Sorts, isso já seria bastante. Entretanto, e evidentemente, não é bem assim que as coisas se passam. $\mathrm{Na}$ verdade, os primeiros trabalhos de FavretSaada (reapresentados em Favret-Saada 2005) como antropóloga remontam ao final da década de 1950, quando investigou sistemas segmentares árabes e bérberes no norte da África, em campos relativamente próximos a seu local de nascimento no sul da Tunísia (em 1934, em uma família de origem judaica). Após a independência da Argélia, Favret-Saada mudou-se para a França, onde os acontecimentos de maio de 1968 fizeram com que decidisse concentrar sua pesquisa, tendo em vista não deixar o país em um momento que, como militante política, considerava fundamental. Dessa decisão, e de modo algo tortuoso, nasceu a pesquisa sobre feitiçaria na região do Bocage francês.

Entre as duas temáticas, despontam alguns pontos de contato - o mais sugestivo sendo, sem dúvida, uma certa relação de redundância entre segmentaridade e desenfeitiçamento.
Pois se a primeira é, sabidamente, um modo de promover modalidades de conflito (na conhecida forma das oposiçóes e fissóes segmentares) e de, ao mesmo tempo, regulá-los (na forma das fusóes segmentares ou dos complexos sistemas de vingança e compensação), algo parecido poderia ser dito do enfeitiçamento e de seu combate. Pois trata-se, aqui também, de um conflito ou de uma oposição (entre feiticeiro e enfeitiçado), devidamente sistematizada e, em geral, resolvida pela intervenção de uma terceira instância, o desenfeitiçador, que, no entanto, não aparece como externa e acima das demais (como ocorreria com uma regulação estatal ou médica de conflitos ou perturbações), e sim como um aliado e um duplo da vítima contra seu inimigo. Nesse sentido, a violência e as formas de, ao mesmo tempo desencadeá-la e regulá-la, aparecem como tema que de certo modo atravessa não apenas essas duas fases do trabalho da autora bem como aquela que a estas se segue.

Do final da década de 1980 ao início da de 1990, foi em torno da feitiçaria e de suas implicaçóes (como modalidade de violência, como parte de práticas terapêuticas, como locus de afetos, como questão para a etnografia e a antropologia...) que se concentrou o trabalho de FavretSaada. A partir daí, um novo tema - sem dúvida relacionado aos anteriores - passou a ocupar sua atenção, a blasfêmia e o projeto de elaboração de uma antropologia da blasfêmia. Atenção suscitada, em parte, pelas reaçóes ao chamado Caso Rushdie e à exibição do filme Amem, de CostaGavras, mas também pelo impacto da constatação de que "religióes que sempre se detestaram" se uniam "contra a modernidade 'blasfemadora" (Favret-Saada 2004a).

Essa antropologia da blasfêmia, por sua vez, conduziu Favret-Saada à elaboração de um trabalho (em colaboração, mais uma vez, com Josée Contreras, psicanalista que com ela trabalhou em outras ocasióes, especialmente na 
edição de parte de suas notas de campo - Favret-Saada 1981a) acerca das relaçóes entre o cristianismo e os judeus na Europa nos últimos dois séculos. Assim como ao que deve ser seu próximo livro, que examinará como, a partir de 1880, as apresentaçóes teatrais da Paixão de Cristo passaram a ser condenadas por diversas igrejas protestantes, às quais, não obstante, não apenas não estendiam essa condenação às exibiçôes cinematográficas da mesma Paixão, como até mesmo as incentivavam.

Não é difícil, pois, perceber que na obra de Jeanne Favret-Saada agenciam-se, de forma muito singular, afetos muito diferentes: alguns ligados à sua história pessoal, outros às suas opçóes éticas e políticas, outros, ainda, relacionados com a antropologia como campo de saber, e assim por diante. Mas uma das originalidades de seu trabalho talvez resida no fato de que o principal operador desse agenciamento sejam os afetos suscitados ou revelados em uma experiência vivida da alteridade, seja no trabalho de campo, seja por outros meios. O que produz resultados que, evidentemente, reagem sobre os próprios afetos agenciados: "há, em mim, uma espécie de perpétua retroação entre um modo náo partidário de ser em política e um modo náo escolar de fazer a pesquisa" (FavretSaada 1984).

\section{Referências bibliográficas}

Além dos textos acima citados, esta bibliografia, ainda que incompleta, reúne a maior parte dos trabalhos de Jeanne Favret-Saada. Seu último posto acadêmico foi o de diretora de pesquisa na École Pratique des Hautes Études, titular da cadeira de etnologia religiosa da Europa.

1966. "La Segmentarité au Maghreb”. L'Homme, VI: 105-111.

1967. "Le Traditionnalisme par Excès de Modernité". Archives Européennes de Sociologie, VIII: 71-93.
1968. "Relations de Dépendance et Manipulation de la

Violence en Kabylie”. L'Homme, VIII: 18-44.

1977a. Les Mots, la Mort, les Sorts. Paris: Gallimard.

1977b. "Excusez-Moi, je ne Faisais que Passer". Les Temps Modernes, 371: 2089-2103.

1981a. Corps pour Corps. Paris: Gallimard (em colaboração com Josée Contreras).

1981b. "Sorcières et Lumières". In Jeanne Favret-Saada \& Josée Contreras. Corps pour Corps. Paris: Gallimard, pp. 333-363.

1981c. “Corps pour Corps”. Les Temps Modernes, 416: 1589-1607 (em colaboração com Josée Contreras).

1984. “Jeanne Favret-Saada”. In Idées Contemporaines.

Entretiens Le Monde. Paris: La Découverte.

1985. "L'Embrayeur de Violence: Quelques Mécanismes

Thérapeutiques du Désorcèlement" In J. Contreras et alii. Le Moi et l'Autre. Paris, Denoël, pp. 95-148.

1985. "La Thérapie sans le Savoir". Nouvelle Revue de Psychanalyse, 31.

1989a. "La Genése du 'Producteur Individuel'. In Annie

M.D. Lebeuf et alii. Singularités. Textes pour Éric de

Dampierre. Paris: Plon, pp. 485-496.

1989b. "Unbewitching as Terapy". American Ethnologist, 16 (1): 40-56.

1990a. "Etre Affecté". Gradhiva. Revue d'Histoire et d'Archives de l'Anthropologie, 8: 3-9.

1990b. "Ah! La Féline, la Sale Voisine...". Terrain, 14: 20-31 (em colaboração com Josée Contreras). [http:// terrain.revues.org/document2968.html]

1991a. "Sale Histoire". Gradhiva. Revue d'Histoire et d'Archives de l'Anthropologie, 10: 3-10.

1991b. "Le Désorcèlement Comme Thérapie". Ethnologie Française, 2.

1991c. "Rushdie et Compagnie. Préalables à une Anthropologie du Blasphème”. Ethnologie Française, 3.

1994. "Weber, les Émotions et la Religion”. Terrain, 22: 93-

108. [http://terrain.revues.org/document2968.html] 1995. "Liaisons Fatales". Esprit, 12.

2000. "La-Pensée-Lévi-Strauss". ProChoix, 13: 13-18.

[http://www.prochoix.org/pdf/levi-strauss.pdf]

2002. “Amen: une 'Juste' Polémique?”. ProChoix, 21.

2004a. "Glissements de Terrains Entretien avec Jeanne

Favret-Saada". Vacarme, 28. [http:/www.vacarme. eu.org/article449.html]

2004b. Le Christianisme et ses Juifs. 1800-2000. Paris: Seuil (em colaboração com Josée Contreras).

2005. Algérie, 1962-1964, Essais d'Anthropologie Politique. Paris: Éd. Bouchene. 